\title{
Toxoplasma gondii seropositivity in pregnancies with normal delivery and complicated with abortion
}

\author{
Burcu Dinçgez Çakmak, Betül Dündar, Feyza Bayram, Gülten Özgen
}

Department of Obstetrics and Gynecology, University of Health Sciences, Bursa Yüksek Ihtisas Training and Research Hospital, Bursa, Turkey

DOI: 10.18621 eurj.339882

\begin{abstract}
Objective: Toxoplasma infection during pregnancy may cause remarkable mortality and morbidityin fetus due to transplacental transmission. It has fetal consequences such as abortion, stillbirth and congenital malformations. In the Turkish literature, there is limited investigations evaluating the prevalence of Toxoplasma gondii among pregnancies complicated with abortion. The aim of this study is to compare the Toxoplasma seropositivity between pregnancies with normal delivery and complicated with abortion.

Methods: This is a retrospective, single center study conducted between May 2015 and June 2016. We included 412 patients in the study group and 828 patients in the control group. The study group (Group 1) was compromised of pregnants whose pregnancies were complicated with abortion and the control group (Group 2) was pregnants with normal delivery. Toxoplasma IgM and IgG seropositivity were compared between two groups.

Results: There was no difference between two groups in terms of sociodemographic features $(p>0.05)$. Toxoplasma IgM was positive in $62(5 \%)$ patients and $\operatorname{IgG}$ was positive in $282(22.9 \%)$ patients in all groups. In subgroup analysis Toxoplasma IgM was found to be positive in 27 (6.6\%) patients in Group 1 and $35(4.2 \%)$ patients in Group 2. Moreover, Toxoplasma IgG was positive in $125(30.6 \%)$ patients in Group 1 and in 157 $(19.2 \%)$ patients in Group 2. Toxoplasma IgM and Toxoplasma IgG were significantly higher in Group $1(p=$ 0.023 and $p=0.016$, respectively).

Conclusion: We concluded that Toxoplasma seropositivity is high in our country and routine screening is essential for pregnancies. Toxoplasmosis may play a role in the etiology of abortion.
\end{abstract}

Keywords: Abortus, pregnancy, toxoplasmosis, toxoplasma immunglobuline

Received: September 26, 2017; Accepted: December 6, 2017; Published Online: February 14, 2018

\section{$T$} oxoplasma gondii, which belongs to TORCH (Toxoplasma gondii, Rubella, Cytomegalovirus and Herpes simplex) group, is an intracelullar obligate parasite with a complex life cycle [1]. Infection is transmitted to humans by ingestion of uncooked meat containing live organisms or by vegetables, fruits and water that are contaminated by oocytes $[2,3]$.
Although serologic positivity of toxoplasma is generally asymptomatic, during pregnancy this infection may cause remarkable mortality and morbidity in fetus due to transplacental transmission. While congenital transmission is most common during last trimester with a ratio of $70-80 \%$, it is $10-15 \%$ in the first trimester. However the risk of severe

Address for correspondence: Burcu Dinçgez Çakmak, MD., University of Health Sciences, Bursa Yüksek Ihtisas Training and Research Hospital, Department of Obstetrics and Gynecology, Emniyet Caddesi No:35, Yuldırım, Bursa, Turkey 
congenital sequela is much higher in the first trimester [4]. It is a preventable cause of severe fetal consequences such as abortion, still-birth and congenital malformations. It can result in central nervous system anomalies, mental and physical retardation, blindness, cerebral calcifications, pneumonia, hepatitis, myocarditis, hydrocephalus, microcephalus and chorioretinitis [5-8]. Fortunately, spiramycin treatment following confirmation of maternal infection is known to prevent the fetal transmission and congenital infection [9]. However, it is still controversial whether screening of $T$. gondii is essential. Since, the seropositivity ratios are high in our country screening is currently being suggested.

T. gondii canbe determined in as high as $1 / 3$ of world population. This frequency can change according to geographical regions, dietary habitutes, socioeconomic status and age [1]. In previous studies, the seropositivity of toxoplasmosis in women isreported to be $43.8 \%$ for Spain, $11 \%$ for USA and $63.7 \%$ for Iran [10]. In our country, this ratio is reported to be between $25.2 \%$ to $69.5 \%$ [11, 12]. Among pregnant women the prevalence of T. gondii is stated as 9.1\% for England, 6.1\% for Mexico, $43.8 \%$ for France, 35\% for Switzerland and 33.9-60.4\% for Turkey $[6,10,13,14]$. Worldwide prevalence of $T$. gondii among pregnancies complicated with abortion is given to be between $17.5 \%$ and $79.03 \%$ [15-17]. In the Turkish literature, there is limited investigations evaluating the prevalence of $T$. gondii seropositivity among pregnancies complicated with abortion and the relevant data is quite limited.

The aim of this study is to compare the $T$. gondii seropositivity between pregnancies with normal delivery and the ones complicated with abortion.

\section{METHODS}

This is a retrospective, single center study which was conducted in a university affiliated research and training hospital between May 2015 and June 2016.

A total of 1240 pregnancies, between 18-40 years of age were included in this study.There were 412 patients in the study group and 828 patients in the control group. The study group was compromised of pregnant women whose pregnancies were complicated with first trimester abortion and the control group was pregnants with normal delivery. We excluded patients whose Toxoplasma seropositivity and pregnancy outcomes were unavailable.

Demographic, clinical and laboratory parameters of patients were obtained from the systemic medical records of the study center. Also, Toxoplasma Immunglobuline (Ig) M and $\mathrm{G}$ values were obtained from patients' files. Toxoplasma specific IgM and IgG values were analyzed by micro-ELISA (Roche, cobalt E601). The positive value for anti-Toxoplasma IgM index was accepted as $>1.0 \mathrm{IU} / \mathrm{ml}$, the borderlinevalue was $\geq 0.8$ and $\leq 1.0 \mathrm{IU} / \mathrm{ml}$ and the negative value was $<0.8 \mathrm{IU} / \mathrm{ml}$. Also anti-Toxoplasma IgG index was accepted as positive for values $>3.0 \mathrm{IU} / \mathrm{ml}$, as borderline for values $\geq 1.0$ and $\leq 3.0 \mathrm{IU} / \mathrm{ml}$ and as negative for values $<1.0 \mathrm{IU} / \mathrm{ml}$. The ratios of seropositivity of Toxoplasma $\operatorname{IgM}$ and $\operatorname{IgG}$ were calculated.

Table 1. Socio-demographic characteristics of the patients

\begin{tabular}{lccc}
\hline & $\begin{array}{c}\text { Abortus } \\
(\mathbf{n}=\mathbf{4 1 2})\end{array}$ & $\begin{array}{c}\text { Normal Delivery } \\
(\mathbf{n}=\mathbf{8 2 8})\end{array}$ & p value \\
\hline Age (years) & $27.6 \pm 11.4$ & $29.1 \pm 9.87$ & 0.921 \\
Gravida (n) & $3(1: 5)$ & $3(1: 6)$ & 0.708 \\
Parity (n) & $2(1: 4)$ & $2(1: 5)$ & 0.632 \\
Residence & & & 0.443 \\
$\quad$ Urban & $229(55.6 \%)$ & $418(50.5 \%)$ & \\
$\quad$ Rural & $183(44.4 \%)$ & $410(49.5 \%)$ & 0.826 \\
$\quad$ Education & & & \\
$\quad$ Plliterate & $52(12.6 \%)$ & $97(11.7 \%)$ & \\
$\quad$ Secondaryary & $116(28.2 \%)$ & $25.3(30.6 \%)$ & \\
$\quad$ High School & $187(45.4 \%)$ & $365(44.2 \%)$ & \\
\hline
\end{tabular}


All procedures performed in studies involving human participants were in accordance with the ethical standards of the institutional and/or national research committee and with the 1964 Helsinki declaration and its later amendments or comparable ethical standards. For retrospective studies, ethics committee approval is not required.

\section{Statistical Analysis}

Statistical analyses were performed with SPSS software (IBM Corp. Released 2012. IBM SPSS Statistics for Windows, Version 21.0. Armonk, NY: IBM Corp.). For group comparisons, independent samples $t$ test or Mann Whitney $U$ test were used according to normality test results. Variables were demonstrated as mean \pm standard deviation or median values. A $p$ value $<0.05$ was considered as statistically significant. Also, categorical variables were shown as percentages and were compared by Chi-square or Fisher's exact test.

\section{RESULTS}

The mean age of all participants was $28.4 \pm 10.3$ years. Mean gravida was $3(1: 5)$ and mean parity was 2 (1:4). The patients were divided into two subgroups: pregnancies complicated with abortus (Group 1) and pregnancies with normal delivery (Group 2). Demographic characteristics of the study $(n=412)$ and control $(n=828)$ group were presented in Table 1. There was no difference between two groups in terms of age, gravida, parity, education status and residency $(p>0.05)$.

According to the $T$. gondii seropositivity, Toxoplasma IgM was positive in $62(5 \%)$ patients and Toxoplasma IgG was positive in $282(22.9 \%)$ patients in all groups. A total of 47 patients were anti-
Table 2. The distribution of anti-ToxoplasmaIgM and antiToxoplasma $\mathrm{IgG}$

\begin{tabular}{lcc}
\hline & $\begin{array}{l}\text { Anti-Toxoplasma } \\
\text { IgM Positive } \\
(\mathbf{n}=62)\end{array}$ & $\begin{array}{l}\text { Anti- } \\
\text { Toxoplasma } \\
\text { IgM Negative } \\
(\mathbf{n}=1178)\end{array}$ \\
\hline $\begin{array}{l}\text { Anti-Toxoplasma } \\
\text { IgG Positive } \\
(\mathbf{n = 2 8 2 )}\end{array}$ & $47(3.8 \%)$ & $235(19 \%)$ \\
$\begin{array}{l}\text { Anti-Toxoplasma } \\
\text { IgG Negative } \\
(\mathbf{n}=958)\end{array}$ & $15(1.2 \%)$ & $943(76 \%)$ \\
\hline
\end{tabular}

Toxoplasma IgG positive and anti-Toxoplasma IgM positive group. The distribution of both antiToxoplasma IgG and anti-Toxoplasma IgM was demonstrated in Table 2. In subgroup analysis Toxoplasma $\operatorname{IgM}$ was found to be positive in 27 (6.6\%) patients in Group 1 and 35 (4.2\%) patients in Group 2. The seropositivity of Toxoplasma IgM was statistically significantly higher in pregnancies complicated with abortus $(p=0.023)$. Moreover, Toxoplasma IgG was positive in 125 (30.6\%) patients in Group 1 and in 157 (19.2\%) patients in Group 2 (Table 3). In addition, the seropositivity of Toxoplasma IgG was statistically significantly higher in pregnancies complicated with abortus $(p=0.016)$.

\section{DISCUSSION}

Prevention, detection and management of congenital toxoplasmosis is a crucial issue for fetal well-being in daily obstetric practice. It has catastrophic consequences such as cephalic abnormalities, retinochoroiditis, blindness, epilepsy, retardation of psychomotor and mental functions, trombocytopenia and anemia [18, 19]. Although $T$.

Table 3. Toxoplasma seropositivity of the patients

\begin{tabular}{lcccc}
\hline & $\begin{array}{c}\text { Total } \\
(\mathbf{n}=\mathbf{1 2 4 0})\end{array}$ & $\begin{array}{c}\text { Abortus } \\
(\mathbf{n = 4 1 2})\end{array}$ & $\begin{array}{c}\text { Normal Delivery } \\
(\mathbf{n}=\mathbf{8 2 8})\end{array}$ & $p$ value \\
\hline $\begin{array}{l}\text { Anti-Toxoplasma IgM } \\
\text {-Positive }\end{array}$ & $62(5 \%)$ & $27(6.6 \%)$ & $35(4.2 \%)$ & 0.023 \\
-Negative & $1178(95 \%)$ & $385(93.4 \%)$ & $793(95.8 \%)$ & \\
$\begin{array}{l}\text { Anti-Toxoplasma } \text { IgG } \\
\text {-Positive }\end{array}$ & $282(22.9 \%)$ & $125(30.6 \%)$ & $157(19.2 \%)$ & 0.016 \\
-Negative & $958(77.1 \%)$ & $287(69.4 \%)$ & $671(80.8 \%)$ & \\
\hline
\end{tabular}


gondii infection which occurs up to 3 months before conception have nearly no risk for fetus, the rate of transmission varies between $60-81 \%$ in the third trimester [20]. Therefore, the confirmation of primary infection is critical to evaluate the risk of transmission and provide appropriate therapy and counseling. It is controversial whether routine screening for $T$. gondii is essential among pregnant women all over the world. Generally, decision on routine screening depends on the prevalence of infection, testing costs, sensitivity of screening tests and limitations of treatment effectiveness [21].

The seroprevalence of toxoplasmosis shows a widespread distribution all over the world depending on age, geographical regions, dietary habits and socioeconomic status [5]. Recent studies have demonstrated that Toxoplasma IgG positivity was 48.7\% in Argentina, 9.1\% in England, 61.6\% in Brasil, $35 \%$ in Switzerland, $6.1 \%$ in Mexico, $50.6 \%$ in Morocco, $43.8 \%$ in France and $10.6 \%$ in China [10, $13,22,23]$. In our country, Saracoglu et al. [24] reported Toxoplasma IgG positivity as $38.1 \%$ in Ankara. Moreover, it has been reported to be $60.4 \%$ in a city of southeastern region, $36 \%$ in a city of eastern region, $30.1 \%$ in a city of western region [14, $25,26]$. In our study Toxoplasma IgG positivity was found to be $22.9 \%$. Our prevalence seems to be lower as compared to our country data. We suggest that the age of our patients was younger than the other studies and our trial center was in the northwestern part of our country which had a better socioeconomic status than the other regions.

Another interesting data of our study is that Toxoplasma IgM positivity was 5\% among our study group. Similarly, in a study of Aynalı et al. [27] they found Toxoplasma IgM positivity as $5.2 \%$ among reproductive women. Also, other studies evaluating Toxoplasma IgM positivity in Turkey showed a prevalence between 0.3\%-9.9\% [26-28].

In the literature, there is a few data about the prevalence of $T$. gondii in pregnancies complicated with abortion. Ghasemi et al. [29] reported Toxoplasma IgG prevalence as $25.5 \%$ in abortion and stilbirth group, and as $26.4 \%$ in control group. Also they reported that Toxoplasma IgM was detected in $6.4 \%$ of the case group and $1.8 \%$ in control group and they concluded that toxoplasmosis might play a role in the etiology of abortion and stillbirth [29]. Tammam et al. [30] demonstrated that Toxoplasma spesific IgG seropositivity was $46.1 \%$ and $\operatorname{IgM}$ was $18.4 \%$ in spontaneous abortus group. They suggested that Toxoplasma seroprevalence is high and antenatal screening is needed in Egypt [30]. In Iran, Toxoplasma IgG seropositivity was $17.5 \%$ in repeated abortion, in Sari 34.21\% and in South Iran 79.03\% [15, 16, 31]. In those studies Toxoplasma IgM prevalence was reported to be $7.89-15.32 \%$. In the study of Anubhuti et al. [32] Toxoplasma IgG was found to be positive in $20 \%$ of women with history of spontaneous abortion and $5 \%$ of women with no bad obstetric history while none of the women were reported to be Toxoplasma IgM positive. The seroprevalence of Toxoplasma IgM was investigated in women with recurrent abortion and it was found as $49.47 \%$. This was much more higher than the seroprevalence in normal delivery group, which was reported as $8.88 \%$ [33]. The cases of abnormal pregnancies, including spontaneous abortions, premature deliveries, embryo damage and birth defects, were shown to have significantly higher seropositivity rates of Toxoplasma $\mathrm{IgM}$ and $\mathrm{IgG}$ as compared to normal pregnancies (7.94\% vs $1.90 \%$ and $19.84 \%$ vs $8.75 \%$, respectively) [34]. In our study, Toxoplasma IgG positivity was $30.6 \%$ in abortus group and $19.2 \%$ in control group. Also, Toxoplasma IgM was positive in $6.6 \%$ of abortus group and in $4.2 \%$ of control group. Consequently, the seropositivity of $\operatorname{IgM}$ and $\operatorname{IgG}$ were significatly higher in pregnancies complicated with abortus as compared to pregnancies with normal delivery and the Toxoplasma seroprevalence was observed to be similar with other countries. Moreover, as it was suggested by the authors of those researches, we suggest that toxoplasmosis is related with first trimester abortus.

\section{CONCLUSION}

In conclusion, Toxoplasma seropositivity is high in our country and routine screening is essential for pregnancies to provide fetal well-being. Toxoplasmosis may play a role in the etiology of abortion and this can be prevented by routine screening and appropriate management.

\section{Conflict of interest}

The authors disclosed no conflict of interest during 


\section{the preparation or publication of this manuscript.}

\section{Financing \\ The authors disclosed that they did not receive any grant during conduction or writing of this study.}

\section{REFERENCES}

[1] Jones JL, Kruszon-Moran D, Wilson M, McQuillan G, Navin T, McAuley JB. Toxoplasma gondii infection in the United States: seroprevalence and risk factors. Am J Epidemiol 2001;154:357-65.

[2] Yang N, Wang D, Xing M, Li C, Li J, Wu A, et al. Seroepidemiology and risk factors of Toxoplasma gondii infection among the newly enrolled undergraduates and postgraduate students in China. Front Microbiol 2017;8:2092.

[3] Miller MA, Gardner IA, Kreuder C, Paradies DM, Worcester KR, Jessup DA, et al. Coastal freshwater runoff is a risk factor for T. Gondii infection of southern sea otters (Enhydralutrisnereis). Int J Parasitol 2002;32:997-1006.

[4] Anonymous. UK Standards for Microbiology Investigation. Investigation of Toxoplasma Infection in Pregnancy. UK: Health Protection Agency, Standards Unit, Microbiology Services Division. 2012.

[5] Kayman T, Kayman M. Seroprevalence of toxoplasmosis among pregnant women in Kayseri. Perinatoloji Dergisi 2010;18:92-6.

[6] Elsheikha HM. Congenital toxoplasmosis: priorities forfurther health promotion action. Public Health 2008;122:335-53.

[7] Abamecha F, Awel H. Seroprevalence and risk factors of Toxoplasma gondii infection in pregnant women following antenatal care at Mizan Aman General Hospital, Bench Maji Zone (BMZ), Ethiopia. BMC Infect Dis 2016;16:460.

[8] Montoya JG, Liesenfeld O. Toxoplasmosis. Lancet 2004;363:196576.

[9] Singh S. Congenital toxoplasmosis: clinical features, outcomes, treatment, and prevention. Trop Parasitol 2016;6:113-22.

[10] Pappas G, Roussos N, Falagas ME. Toxoplasmosis snapshots: global status of Toxoplasma gondii. Int J Parasitol 2009;39:1385-94.

[11] Tekay F, Ozbek E. [The Seroprevalence of Toxoplasma gondii in women from Sanliurfa, a province with a high raw meatball consumption]. Turkiye Parazitol Derg 2007;31:176-9. [Article in Turkish]

[12] Güneş H, Kaya S, Çetin ES, Taş T, Demirci M. [Seroprevalance of Toxoplasmosis in reproductive women]. SDU Tip Fak Derg 2008;15:214. [Article in Turkish]

[13] Alvarado-Esquivel C, Sifuentes-Alvarez A, Narro-DuarteSG. Seroepidemiology of Toxoplasma gondiiinfectionin pregnant women in a public hospital in northern Mexico. BMC Infect Dis 2006;6:113.

[14] Harma M, Harma M, Gungen N, Demir N. Toxoplasmosis in pregnant women in Sanliurfa, SouthEastern Anatolia City, Turkey. J Egypt Soc Parasitol 2004;34:519-25.

[15] Ebadi P, Solhjoo K, Bagheri K, Eftekhar F. Seroprevalence of toxoplasmosis among the women with recurrent spontaneous abortion in comparison with the women with uncomplicated delivery. J Jahrom Univ Med Sci 2011;9:32-6.

[16] Jahromi AS. Anti-toxoplasma antibodies in women with abortion or still birth. J Jahrom Univ Med Sci 2007;4:47-52.

[17] Saki J, Mohammadpour N, Moramezi F, Khademvatan S. Seroprevalence of Toxoplasma gondii in women who have aborted in comparison with the women with normal delivery in Ahvaz, Southwest of Iran. Sci World J 2015;2015:764369.

18] Flatt A, Shetty N. Sero-prevalence and risk factors for toxoplasmosis among antenatal women in London: a re-examination of risk in an ethnically diverse population. Eur J Public Health 2013;23:648-52.

[19] Torgerson PR, Macpherson CNL. The socioeconomic burden of parasitic zoonoses: global trends. Vet Parasitol 2011;182:79-95.

[20] Alavi SM, Alavi L. Toxoplasmosis in Iran: A guide for general physicians working in the Iranian health network setting: A systematic review. Caspian J Intern Med 2016;7: 233-41.

[21] Chaudhry SA, Gad N, Koren G. Toxoplasmosis and pregnancy. Can Fam Physician 2014;60: 334-6.

[22] Berger F, Goulet V, Le Strat Y, Desenclos JC. Toxoplasmosis among pregnant women in France: risk factors and change of prevalence between 1995 and 2003. Rev Epidemiol Sante Publique 2009;57:2418.

[23] Liu Q, Wei F, Gao S, Jiang L, Lian H, Yuan B, et al. Toxoplasma gondii infection in pregnant women in China. Trans $\mathrm{R}$ Soc Trop Med Hyg 2009;103:162-6.

[24] Saracoglu F, Sahin I. [Prevalence of Toxoplasmosis in a pregnant population and seroconversion rate of seronegative pregnants]. T Klin Jinekol Obst 2001;11:326-8. [Article in Turkish]

[25] Ertug S, Okyay P, Turmen M, Yuksel H. Seroprevalence and risk factors for Toxoplasma infection among pregnant women in Aydin province, Turkey. BMC Public Health 2005;5:66.

[26] Efe Ş, Kurdoğlu Z, Korkmaz G. [Seroprevalance of Cytomegalovirus, Rubella and Toxoplasma antibodies in pregnant women of Van Region]. Van Tip Derg 2009;16:6-9. [Article in Turkish] [27] Aynalı A, Cicioglu, Arıdogan B, Tola E, Onalı S, Sesli Çetin E. [Evaluation of anti-Toxoplasma IgM and IgG seropositivity among women in reproductive period, who admitted to Suleyman Demirel University Hospital]. Turk Hij Den Biyol Derg 2016;73:33-8. [Articie in Turkish]

[28] Bakıcı MZ, Nefesoglu N, Erandac M. Results of screening for Torch of blood samples collected in a microbiology laboratory. CÜ Tip Fak Derg 2002;24:5-8. [Articie in Turkish]

[29] Ghasemi FS, Rasti S, Piroozmand A, Bandehpour M, Kazemi B, Mousavi SG, et al. Toxoplasmosis-associated abortion and stillbirth in Tehran, Iran J Matern Fetal Neonatal Med 2016;29:248-51.

[30] Tammam AE, Haridy MAM, Abdellah AH, Ahmed SR, Fayed HM, Alsammani MA. Seroepidemiology of Toxoplasma gondii infection in women with first trimester spontaneous miscarriage in Qena Governorate, Egypt. J Clin Diagn Res 2013;7:2870-3.

[31] Sharif M, Ajami A. Serological survey of toxoplasmosis in women with abortion or still birth referring to women clinic in Sari, 1997-1998. J Mazandaran Univ Med Sci 1999;26:13-8.

[32] Anubhuti, Roy RR, Mittra JP, Begum SJ. Seroprevalence of Toxoplasma gondii in spontaneous abortions in pregnant women. J Evol Med Dental Sci 2015;4:6763-8.

[33] Zargar AH, Masoodi SR, Laway BA, Sofi BA, Wani AI. Seroprevalence of toxoplasmosis in women with repeated abortions in Kashmir. J Epidemiol Community Health 1998;52:135-6.

[34] Zhang SF, Song RH. Toxoplasma gondii infection status in abnormal pregnancy women. Zhongguo Xue Xi Chong Bing Fang Zhi Za Zhi 2014;26:437-8, 452. [Articie in Chinese] 